\title{
Pengaruh Kredit Investasi dan Kredit Modal Kerja Terhadap Kesejahteraan Masyarakat Kabupaten/Kota di Jawa Timur
}

\author{
Agus Sumanto \\ Fakultas Ekonomi Universitas Negeri Malang \\ agussumantoblog@gmail.com
}

\begin{abstract}
The development of investment credit and working capital credit in the regencies/ municipalities in East Java so rapidly, with an average of over $20 \%$ per year from 2003 to 2012. The benefit of the credit on the increase in output, employment and the social welfare need to be evaluated. This study finding that the benefit of the investment credit for the social welfare is negative, but the usefulness of working capital credit is positive. After the analysis is done, the cause is the shift of investment from labor-intensive to capital-intensive investments, where in capital intensive investment, labor absorption is low. As a further consequence, social welfare decreased despite increase in investment credit occur. It is advisable to make an investment credit policies that easy accessable to micro, small and cooperatives that can absorb more labor than of medium and large enterprises.
\end{abstract}

Keywords: investment credit, working capital credit, output, labour absorption

\section{PENDAHULUAN}

Otonomi daerah di Indoensia sudah berjalan lebih dari 15 tahun, terhitung mulai tahun 2000, semenjak diberlakukannya undang-undang No 22 tahun 1999 tentang pemerintahan Daerah dan UU No 25 tahun 1999 tentang Perimbangan Keuangan Pusat-Daerah. Dalam era otonomi daerah, tiap-tiap daerah leluasa mengembangkan perekonomiannya, sesuai potensi dan karakteristik sumberdaya daerah masing-masing, berbeda dengan era sebelumnya yang bersifat sentralistik.

Salah satu tujuan dari otonomi daerah dari segi ekonomi adalah kesejahteraan. Hal ini bisa tercapai bila semua kebutuhan masyarakat terpenuhi secara layak. Meskipun secara rata-rata pendapatan perkapita meningkat, tetapi masih terdapat prosentase kemiskinan yang tinggi di suatu daerah, belum disebut kesejahteraan. Todaro (Todaro and Smith, 2006:250) mengemukakan bahwa kesejahteraan suatu masyarakat merupakan fungsi dari pendapatan perkapita, ketimpangan pendapatan dan kemiskinan absolut. Ketimpangan pendapatan yang tinggi menurunkan kesejahteraan masyarakat karena terbukti meningkatkan kriminalitas, meningkatkan kecemberuan sosial dan menurunkan partisipasi masyarakat dalam pembangunan.

Berbeda dengan Todaro, Sen menyatakan bahwa kesejahteraan adalah peningkatan kapabilitas setiap individu dalam masyarakat. Kesejahteraan manusia akan tinggi jika mampu membaca, menulis, menyatakan pendapat, memberikan suara dan tentu saja mempunyai kemampuan untuk memenuhi kebutuhan hidupnya. Indikator pembangunan yang hanya memusatkan pada pendapatan adalah tidak tepat. Seseorang yang kaya dalam arti pendapatannya tinggi, tetapi 
tidak bisa berpartisipasi dalam bidang politik, atau tidak mempunyai kebebasan, maka bisa dikatakan "miskin". Sen mengartikan bahwa pembangunan dalam arti luas berarti pembangunan manusia secara menyeluruh untuk meningkatkan kapabilitas manusia (Sen, 1999:87).

Apapun definisi kesejahteraannya, kesimpulan akhirnya adalah satu, yaitu kesejahteraan tinggi jika segala kebutuhan manusia terpenuhi secara layak. United Nations Development Programme (UNDP) mulai tahun 1990 telah menyusun suatu indikator pembangunan yang dapat menunjukkan kemajuan manusia berdasarkan faktor-faktor: rata-rata usia harapan hidup, rata-rata lama sekolah, angka melek huruf, dan kesejahteraan secara keseluruhan. Indikator kesejahteraan masyarakat yang disusun UNDP dikenal dengan Human Development Index (HDI) atau Indeks Pembangunan Manusia (IPM) (UNDP 1994: 94).

Untuk meningkatkan kesejahteraan masyarakat tersebut setiap daerah seharusnya berlomba-lomba memacu investasinya. Jika investasi tinggi, maka Produk Domestik Regional Bruto (PDRB) akan tinggi. Selanjutnya tingginya PDRB akan dikonversi masyarakat dalam berbagai bentuk kesejahteaan, yaitu tingginya tingkat pendidikan, tingginya daya beli dan kemampuan untuk membayar biaya kesehatan. Investasi yang tinggi juga menyebabkan penyerapan tenaga kerja yang tinggi. Jika banyak tenaga kerja di daerah yang terserap, berarti semakin memeratakan distribusi pendapatan.

Langkah pemerintah-pemerintah daerah untuk memacu investasi antara lain adalah dengan mengkondisikan aksesebilitas pendanaan investasi bagai dunia usaha di daerahnya. Pemerataan mendapatakn akses perbankan yang mudah akan mempertinggi penyaluran kredit investasi (investment credit) dan kredit modal kerja (working capital credit). Kedua kredit tersebut merupakan kredit jangka panjang dan kredit jangka pendek untuk menambah stok barang modal termasuk mesin-mesin, peralatan, tanah dan persediaan. Oleh karena itu pengkondisian pemerataan dan kemudahan akses perbankan merupakan hal yang penting, yang berupa kemudahan ijin usaha, kemudaha mendapatkan lokasi, kemudahan promosi/marketing dan kemudahan yang berhubungan dengan sumber daya manusia misalnya peraturan ketenagakerjaan di daerah.

Aksesebilitas dana investasi yang tinggi, terutama dari perbankan baik konvensional maupun syariah, ternyata belum tentu menjamin investasi yang tinggi. Jika infrastruktur di suatu daerah buruk, pelayanan birokrasi yang tidak memuaskan, maka investasi tetap akan rendah, meskipun dana yang ditawarkan perbankan melimpah. Investor yang mengalami kerugian, akan menghentikan investasi dan melakukan relokasi ke daerah lain. Demikian pula jika suku bunga tinggi sehingga investor tidak mendapatkan keuntungan, akan berhenti untuk menggunakan dana dari perbankan.

Untuk mengevaluasi manfaat dana investasi, yaitu kredit investasi dan kredit modal kerja terhadap kesejahteraan masyarakat maka perlu dilakukan studi dengan variabel intervening PDRB dan penyerapan tenaga kerja. Lokasi studi dipilih di Jawa Timur karena merupakan Provinsi dengan kabupaten/kota yang terbesar, yaitu 38 kabupaten/kota. Kontribusi PDRB Jawa Timur terhadap perekonomian nasional sangat sifinifikan, yiatu 14,85\% (BPS, 2012). Terdapat cukup tinggi ketimpangan pendapatan di Jawa Timur antara daerah yang mempunyai PDRB tinggi dengan daerah-daerah yang mempunyai PDRB rendah. Dengan alasan tersebut maka studi ini bisa dijadikan kajian kebijakan investasi 
seperti apa yang bisa cepat mempertinggi tingkat kesejahteraan masyarakat. Kegunaan studi ini yang lain adalah untuk mengevaluasi sudahkah dana perbankan memberikan peranan peningkatan PDRB, penyerapan tenaga kerja dan kesejahteraan masyarakat pada akhirnya?

\section{KAJIAN PUSTAKA}

Peranan investasi di dalam meningkatkan output dalam pemikiran Keynesian adalah adanya hubungan antara perubahan ouput $(\Delta \mathrm{Y})$ sebagai akibat dari perubahan investasi $(\Delta \mathrm{I})$ dikalikam dengan angka pengganda $(\mathrm{m})$ dengan formula:

$$
\Delta \mathrm{Y}=\mathrm{m} . \Delta \mathrm{I}
$$

Dengan formula tersebut Harrod dan Domar (Jhingan, 1983) menurunkan rumus lebih lanjut bahwa perekonomian bisa tumbuh tergantung dari jumlah tabungan dan efisiensi penggunaan kapital. Semakin tinggi bagian pendapatan yang ditabung (s) dan semakin rendah $\mathrm{k}$, dimana $\mathrm{k}$ adalah $\mathrm{K} / \mathrm{Y}$, maka perkonomian bisa tumbuh dengan cepat:

$$
\Delta \mathrm{Y} / \mathrm{Y}=\mathrm{s} / \mathrm{k}
$$

$\Delta \mathrm{Y} / \mathrm{Y}$ disebut dengan pertumbuhan ekonomi, sedangkan $\mathrm{k}$ disebut juga Capital Ouput Ratio (COR), yang menunjukkan efisiensi kapital di dalam memproduksi ouput. Semakin rendah k semakin baik.

Selain investasi akan meningkatkan ouput, pada gilirannya akan meningkatkan penyerapan tenaga kerja. Untuk kasus kabupaten/kota di Jawa Timur bisa mengadopsi model Lewis tentang kelebihan supply tenaga kerja di daerah-daerah pedalaman/pinggiran yang mana biasanya berbasis pertanian. Model Lewis mengasumsikan bahwa terjadi supply tenaga kerja yang tidak terbatas di sektor subsisten di negara-negara sedang berkembang (Jhingan, 1983). Upah yang rendah di sektor subsisten karena produk marginal adalah nol menyebabkan investasi di sektor kapitalis menggerakkan tenga kerja berpindah ke sektor kapitalis terus-menerus sampai akhirnya terjadi kesamaan upah antara sektor kapitalis dan sektor subsisten.

Penyerapan tenaga kerja tidak hanya terjadi karena investasi, tetapi juga merupakan turunan dari besarnya output. Okun telah menyatakan bahwa hubungan antara pengangguran dan ouput adalah negatif. Penurunan output sebesar 2\% akan meningkatkan pengangguran setara 1\% (Dornbush et al., 2008; Samuelson and Nordhaus, 2001). Pernyataan ini bisa dibalik bahwa Peningkatan output sebesar $2 \%$ akan meningkatkan penyerapan tenaga kerja sebesar $1 \%$. Ketika output meningkat, pendapatan orang meningkat, permintaan barang dan jasa meningkat yang mengakibatkan pengusaha mulai menambah tenaga kerja untuk menambah produksi. Ketika kondisi output mengalami penurunan, pengusaha mengurangi penggunaan tenaga kerja untuk efisiensi.

Karena tujuan akhir dari pembangunan ekonomi adalah kesejahteraan masyarakat, maka peningkatan ouput dan penyerapan tenaga kerja pada akhirnya harus dihubungan dengan meningkat tidaknya kesejahteraan masyarakat. Dari berbagai definisi kesejahteraan masyarakat, untuk mengukur pencapaian antara daerah yang satu dengan yang lain, lebih baik digunakan Indeks Pembangunan Manusia (IPM).

United Nations Development Programme (UNDP) mulai tahun 1990 telah menyusun suatu indikator kesejahteraan manusia yang dapat menunjukkan 
kemajuan manusia berdasarkan faktor-faktor: rata-rata usia harapan hidup, ratarata lama sekolah, angka melek huruf, dan kesejahteraan secara keseluruhan. Laporan ini menganggap bahwa pembangunan manusia pada hakikatnya adalah suatu proses memperbesar pilihan-pilihan manusia. Indikator kesejahteraan masyarakat yang disusun UNDP dikenal dengan Human Development Index (HDI) atau Indeks Pembangunan Manusia (IPM) (UNDP 1994: 94).

Human Development Index (HDI) merupakaan perangkat yang sangat bermanfaat untuk mengukur tingkat kesejahteraan antar negara maupun antar daerah (Todaro and Smith, 2006:72-73). Indikator HDI jauh melebihi pertumbuhan konvensional. Pertumbuhan ekonomi penting untuk mempertahankan kesejahteraan rakyatnya, namun pertumbuhan bukan akhir dari pembangunan manusia. Pertumbuhan hanyalah salah satu alat, yang lebih penting adalah bagaimana pertumbuhan ekonomi digunakan untuk memperbaiki kapabilitas manusianya dan bagaimana rakyat menggunakan kapabilitasnya tersebut.

Beberapa penelitian terdahulu belum menganalisis pengaruh investasi swasta terhadap kesejahteraan masyarakat, tetapi sebagian besar masih pada pengaruhnya terhadap output atau pertumbuhan ekonomi. Misalnya penelitian Qin et al. (2006), menguji hubungan kausalitas antara pertumbuhan investasi swasta dan investasi pemerintah dan pertumbuhan GDP. Kesimpulan studi adalah pertumbuhan stok modal (pertumbuhan investasi) tidak mendorong pertumbuhan output secara reguler baik dalam jangka pendek maupun jangka panjang. Outputlah yang mendorong permintaan investasi.

Penelitian oleh Fatihudin (2011) tentang Pengaruh Investasi Swasta dan Investasi Pemerintah terhadap Pertumbuhan Ekonomi, Penyerapan Tenaga Kerja dan Tingkat Kesejahteraan Masyarakat Kabupaten/Kota di Provinsi Jawa Timur, hasilnya adalah investasi swasta berpengaruh signifikan terhadap pertumbuhan ekonomi dan penyerapan tenaga kerja, tetapi tidak signifikan terhadap kesejahteraan masyarakat. Variabel investasi swasta yang dimaksud dalam penelitian ini adalah total investasi yang tercatat di BPS kabupaten/kota.

Sehubungan dengan kredit yang disalurkan perbankan, penelitian oleh Kuniasari (2010) tentang Analisis Pengaruh Kredit Perbankan dan Tenaga Kerja Terhadap Pertumbuhan Ekonomi Di Indonesia : Analisis Sektoral Tahun 2002 2008, menghasilkan kesimpulan bahwa baik total kredit maupun kredit investasi serta tenaga kerja sektoral memiliki pengaruh positif terhadap pertumbuhan ekonomi. Penelitian Alatan dan Basana (2015) tentang pengaruh pemberian kredit sektoral terhadap pertumbuhan ekonomi di Jawa Timur menghasilkan kesimpulan bahwa kredit perbankan memberikan dampak terhadap pertumbuhan ekonomi di Jawa Timur.

Hubungan kompleks antara investasi, pertumbuhan ekonomi, penyerapan tenaga kerja dan kesejahteraan masyarakat telah dideskripsikan dalam penelitian misalnya oleh Sulistiawati (2012), dengan data di 33 provinsi di Indoensia tahun 2006 sampai dengan 2010. Hasilnya adalah investasi tidak signifikan berpengaruh terhadap pertumbuhan ekonomi, investasi berpengaruh signifikan terhadap penyerapan tenaga kerja, di sisi lain pertumbuhan ekonomi berpengaruh tidak signifikan terhadap penyerapan tenaga kerja dan hasil akhirnya adalah pertumbuhan ekonomi dan penyerapan tenaga kerja tidak signifikan terhadap kesejahteraan masyarakat. 


\section{METODE}

Lokasi studi adalah di kabupaten/kota di Provinsi Jawa Timur. Sampel diambil sebanyak 37 daerah yang terdiri dari 30 kabupaten dan 7 kota. Data yang dipakai adalah tahun 2003 sampai dengan tahun 2012 (10 tahun) karena mempertimbangkan kelengkapan data. Sumber data adalah BPS kabupaten/kota, BPS Provinsi Jawa Timur, BPS Pusat.

Studi ini menggunakan 5 variabel. Variabel yang dinyatakan eksogen adalah kredit investasi dan kredit modal kerja, variabel endogen intervening adalah PDRB dan penyerapan tenaga kerja, variabel endogen adalah kesejahteraan masyarakat.

Kredit investasi adalah kredit yang disalurkan bank umum dan BPR yang kegunaannya adalah untuk membeli tanah, gedung, mesin-mesin, barang modal yang akan digunakan untuk produksi dengan jangka waktu kredit lebih dari satu tahun. Kredit modal kerja adalah kredit yang penggunaanya untuk membeli peralatan, persediaan barang dagangan, barang pembantu yang akan digunakan untuk produksi dengan jangka waktu kredit 1 tahun atau lebih. Kredit investasi dan kredit modal kerja diukur dalam satuan Rupiah (Rp).

PDRB adalah jumlah barang dan jasa yang diproduksi oleh kabupaten/kota selama satu tahun menurut 9 sektor sekonomi. PDRB diukur dalam satuan Rupiah (Rp) pada harga konstan. 9 sektor tersebut adalah: (1) Pertanian, Peternakan, Kehutanan dan Perikanan; (2) Pertambangan dan Penggalian ; (3) Industri Pengolahan; (4) Listrik, Gas dan Air Bersih; (5) Konstruksi, Perdagangan, Hotel dan Restoran ; (7) Pengangkutan dan Komunikasi; (8) Keuangan, Real Estate dan Jasa Perusahaan ; (9) Jasa-jasa termasuk jasa pelayanan pemerintah. Setiap sektor tersebut dirinci lagi menjadi sub-sub sektor.

Penyerapan tenaga kerja adalah jumlah penduduk usia 15 tahun ke atas yang bekerja atau membantu bekerja untuk mendapatkan pendapatan/keuntungan, minimal 1 jam selama seminggu tidak terputus. Kegiatan tersebut termasuk juga pola kegiatan pekerja tak dibayar yang membantu dalam suatu usaha/kegiatan ekonomi (BPS Jawa Timur). Penyerapan tenaga kerja diukur dengan jumlah orang/jiwa.

Kesejahteraan masyarakat adalah suatu kondisi dimana masyarakat mempunyai kemampuan untuk memenuhi apa yang diinginkannya. Kesejahteraan masyarakat diwakili oleh Indeks Pembangunan Manusia (IPM). Komponen IPM adalah angka harapan hidup, angka melek huruf, rata-rata lama sekolah dan daya beli. Untuk menghitung IPM lebih dahulu menghitung komponen indeks ke-i dari IPM:

Dimana:

$$
\text { Indeks } X_{(i)}=\frac{X_{(i)}-X_{(\min )}}{X_{(\operatorname{maks})}-X_{(\min )}}
$$

$\mathrm{X}_{(\mathrm{i})} \quad=$ Komponen IPM ke-i

$\mathrm{X}_{(\min )}=$ Nilai minimum dari komponen IPM ke-i

$\mathrm{X}_{\text {(maks) }}=$ Nilai maksimum dari komponen IPM ke-i.

Jenis data yang akan diolah dalam penelitian ini adalah data panel (pooled data), yaitu menggabungkan data runtut waktu (time series) dan cross section. Keunggulan data panel mampu memperhitungkan heterogenitas individu secara eksplisit dengan mengijinkan variabel eksplisit individu, sehingga dapat digunakan untuk membangun perilaku yang lebih kompleks. Besarnya jumlah 
observasi menjadi data panel lebih informatif, lebih variatif dan kolinearitas antar variabel semakin berkurang, dan peningkatan derajad kebebasan (df) sehingga hasil estimasi lebih efisien. Model perilaku yang rumit juga bisa dipelajari dengan data panel, contohnya fenomena ekonomi berskala dan perubahan tehnologi (Gujarati and Porter 2013:237).

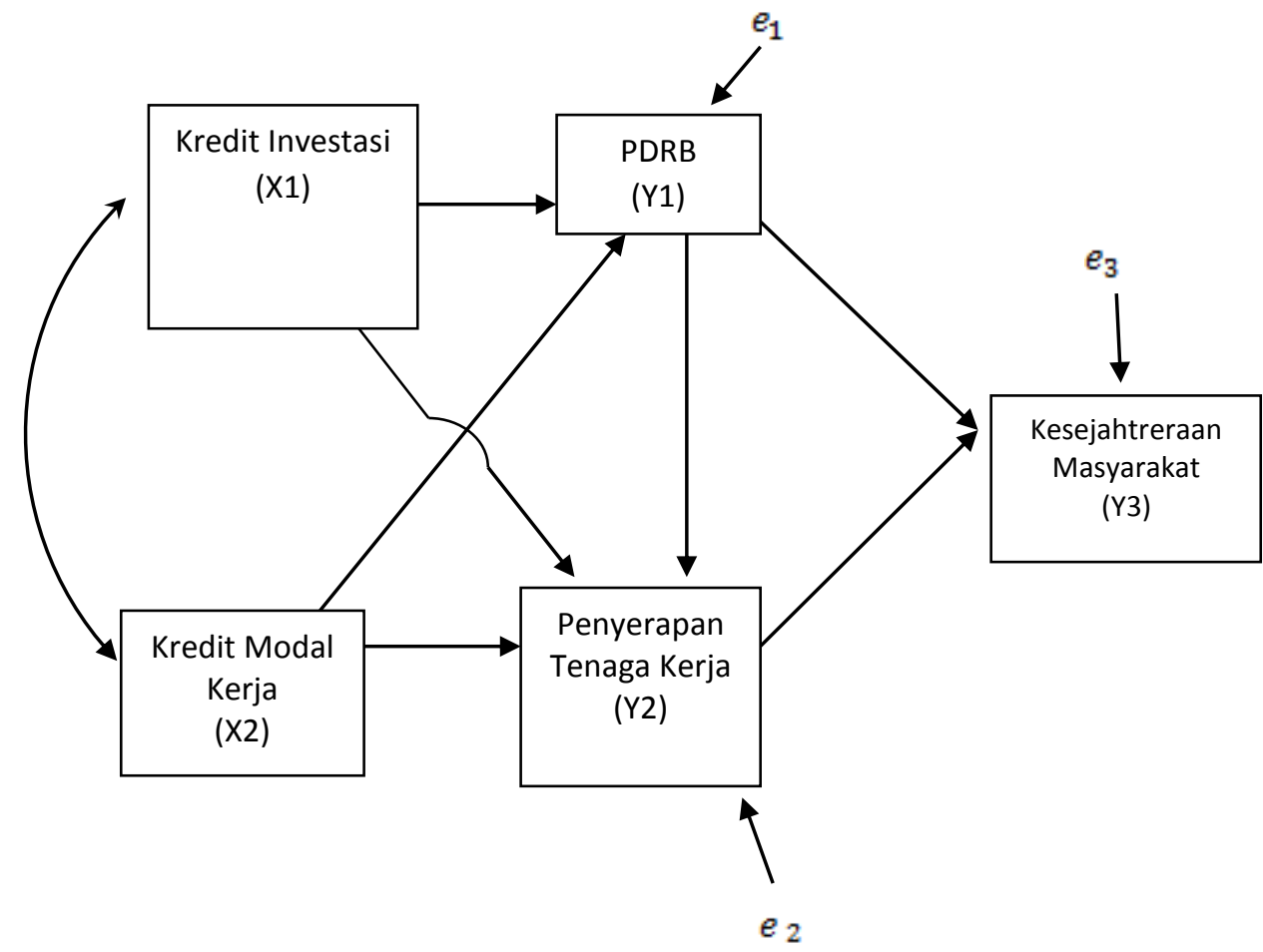

\section{Gambar 1 \\ Diagram Jalur Model}

Teknik analisis yang dipakai dalam penelitian ini adalah analisis jalus (path analysis). Menurut Rutherford (Sarwono 2007:1) analisis jalur adalah teknik untuk menganalisis hubungan sebab akibat yang terjadi pada regresi berganda jika variabel bebasnya mempengaruhi variabel tergantung tidak hanya secara langsung, tetapi juga secara tidak langsung. Sedangkan prinsip-prinsip dasar yang harus dipenuhi dalam analisis jalur diantaranya adalah (Sarwono 2007:2): adanya linearitas (linearity), artinya hubungan antar variabel bersifat linear, adanya aditivitas (additivity), yaitu tidak ada efek-efek interaksi, data berskala interval, semua variabel residual (yang tidak diukur) tidak berkorelasi dengan salah satu variabel dalam model, istilah gangguan (disturbance terms) atau variabel residual tidak boleh berkorelasi dengan semua variabel endogeneous dalam model, adanya multikolinearitas antar variabel independen yang lemah.

Sebelum semua koefisien jalur diukur dan dianalisis, terlebih dahulu disipakan diagram jalur sesuai dengan hubungan teoritis sebagaimana digambarkan dalam Gambar 1.

Berdasarkan diagram jalur tersebut maka bisa dibuat 3 persamaan substruktur: 
1. Substruktur 1:

$$
Y 1_{i t}=\beta_{1}+\beta_{2} X 1_{i t}+\beta_{3} X 2_{i t}+u_{i t}
$$

2. Substruktur 2:

$$
Y 2_{i t}=\beta_{1}+\beta_{2} X 1_{i t}+\beta_{3} X 2_{i t}+\beta_{4} Y 1_{i t}+u_{i t}
$$

3. Substruktur 3:

$$
Y 3_{i t}=\beta_{1}+\beta_{2} Y 1_{i t}+\beta_{3} Y 2_{i t}+u_{i t}
$$

Dimana, X1 adalah Kredit Investasi, X2 adalah Kredit Modal Kerja, Y1 adalah PDRB, Y2 adalah Penyerapan Tenaga Kerja dan Y3 adalah Kesejahteraan Masyarakat.

\section{HASIL DAN PEMBAHASAN}

Dari data yang telah dikumpulkan bisa dideskripsikan sebagai berikut. Perkembangan Kredit investasi yang disalurkan bank-bank umum dan BPR mulai tahun 2003 sampai dengan tahun 2012 rata-rata sebesar 22\% setahun. Suatu perkembangan yang menakjubkan. Dalam nilai nominal, rata-rata kredit investasi yang disalurkan sebesar Rp17,9 triliun, dengan nilai tertinggi tahun 2003 sebesar Rp41,9 triliun. Pertumbuhan kredit modal kerja di kabupaten/kota di Jawa Timur juga sangat tinggi, dengan rata-rata per tahun 20\% antara tahun 2003 sampai dengan 2012.

PDRB kabupaten/kota di Jawa Timur mengalami peningkatan yang berarti, dengan rata-rata peningkatan $6,21 \%$ per tahun. PDRB dari 37 kabupaten/kota pada tahun 2003 adalah sebesar Rp241,3 triliun sedang pada tahun 2012 menjadi Rp391,9 triliun. Terdapat perbedaan yng tinggi antara daerah yang mempunyai PDRB terkecil dengan daerah yang mempunyai PDRB terbesar. Pada tahun 2012 daerah dengan PDRB terkecil adalah Pacitan dengan nilai Rp1,16 triliun sedangkan terbesar adalah Surabaya dengan nilai Rp107 triliun.

Pertumbuhan penyerapan tenaga kerja kabupaten/kota di Jawa Timur mulai tahun 2003 sampai dengan tahun 2012 rata-rata sebesar 1,58\%. Pertumbuhan penyerapan tenaga kerja tertinggi adalah Kota Probolinggo dengan rata-rata pertumbuhan $4,43 \%$ per tahun, sedang pertumbuhan terendah dipunyai oleh Kabupaten Lamongan dengan angka $-0,44 \%$ setahun atau semakin menurun.

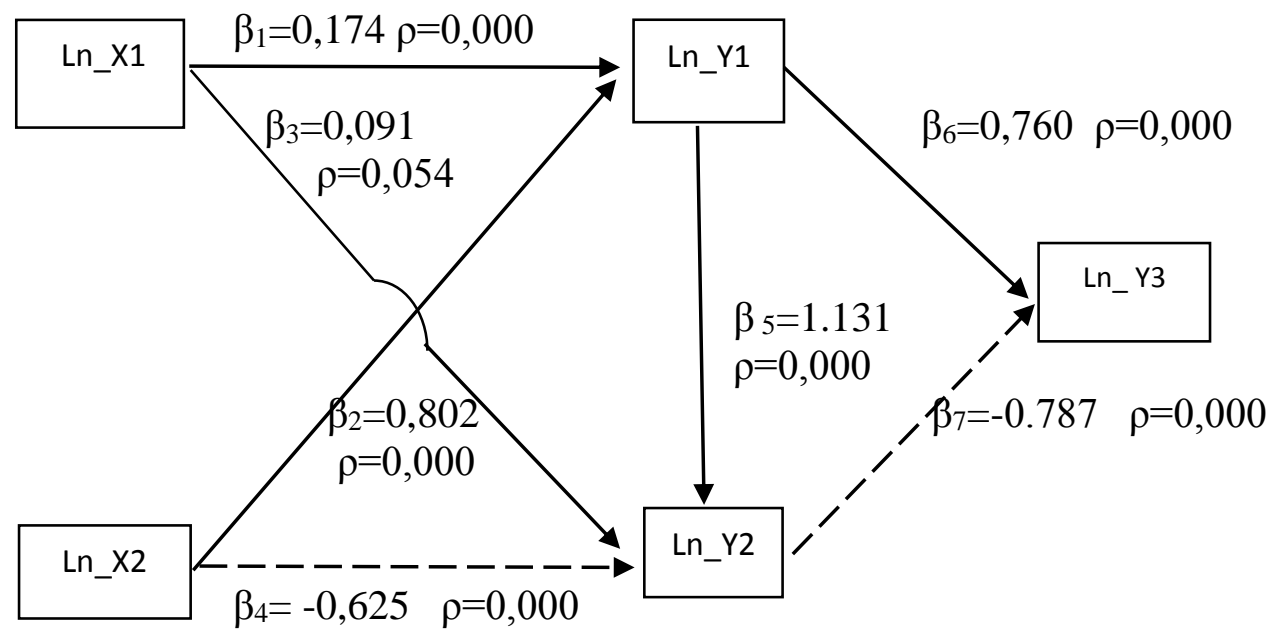


Keterangan:

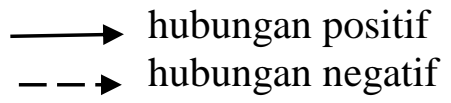

Gambar 2

Hasil Perhitungan Koefisien Jalur

Selanjutnya dilakukan analisis statistik untuk menghitung koefisien jalur. Substruktur 1, 2 dan 3 harus dilakukan tranformasi untuk mengurangi atau menghilangkan adanya autokorelasi dan heteroskedastisitas, sehingga menjadi:

$$
\begin{aligned}
& L n_{-} Y 1_{i t}=\alpha_{1}+\beta_{1} L n_{-} X 1_{i t}+\beta_{2} L n_{-} X 2_{i t}+u_{1 i t} \\
& L n_{-} Y 2_{i t}=\alpha_{2}+\beta_{3} L n_{-} X 1_{i t}+\beta_{4} L n_{-} X 2_{i t}+\beta_{5} L n_{-} Y 1_{i t}+u_{2 i t} \\
& L n_{-} Y 3_{i t}=\alpha_{3}+\beta_{6} L n_{-} Y 1_{i t}+\beta_{7} L n_{-} Y 2_{i t}+u_{3 i t}
\end{aligned}
$$

Dari hasil analisis statistik pada substruktur 1, 2 dan 3 didapatkan hasil seperti tergambar dalam Gambar 2. Semua Koefisien $(\beta)$ signifikan pada tingkat probabilitas lebih kecil atau sama dengan $\alpha=0,05$.

Dengan hasil perhitungan koefisien jalur tersebut selanjutnya dihitung koefisien jalur gabungan dengan hasil:

1. Koefisien jalur gabungan pengaruh kredit investasi terhadap kesejahteraan masyarakat: $-0,094$.

2. Koefisien jalur gabungan pengaruh kredit modal kerja terhadap kesejahteraan masyarakat: 0,387 .

Arti dari hasil perhitungan koefisien jalur gabungan tersebut adalah kredit investasi memberikan pengaruh negatif terhadap kesejahteraan masyarakat. Semakin tinggi kredit investasi, semakin rendah kesejahteraan masyarakat. Kredit moal kerja berpengaruh positif terhadap kesejahteraan masyarakat. Semakin tinggi kredit modal kerja, semakin tinggi kesejahteraan masyarakat.

Hasil dari studi bahwa kredit investasi berpengaruh negatif terhadap kesejateraan masyarakat kabupaten/kota di Provinsi Jawa Timur merupakan temuan studi yang tidak menherankan. Hal in megindikasikan bahwa bidangbidang investasi di Jawa Timur bergeser dari bidang yang sebelumnya adalah padat karya ke bidang yang padat modal. Karena bergeser ke bidang yang padat modal, efek penyerapan tenaga kerja menjadi semakin sedikit per modal yang dikeluarkan. Penyerapan tenaga kerja yang sedikit menyebabkan efek kemakmuran yang semakin sedikit.

Data statistik menunjukkan bahwa pada tahun $2013,91 \%$ jenis usaha yang ada di Indonesia adalah usaha mikro, 8\% adalah usaha kecil dan 1\% adalah usaha sedang dan besar (BPS, 2015a;2015b). Usaha mikro dan kecil menyerap tenaga kerja yang lebih besar dibanding usaha menengah dan besar. secara rata-rata, satu usaha mikro mampu menyerap 1-2 orang tenaga kerja, satu usaha kecil mampu menyerap 15-16 orang tenaga kerja, sedang usaha besar dan sedang mampu menyerap 208-209 tenaga kerja. Dengan investasi sebesar Rp10 miliar pada banyak usaha mikro mampu menyerap setidak-tidaknya 800 tenaga kerja, sedang kalau dijadikan satu usaha besar hanya mampu menyerap 208-209 tenaga kerja.

Besar kecilnya penyerapan tenga kerja mempengaruhi kesejahteraan masyarakat karena akan dikonversikan dalam bentuk kemampuan daya beli, kemampuan membiayai pengeluaran untuk kesehatan sehingga menurunkan angka kematian bayi dan meningkatkan harapan hidup, kemampuan untuk memperoleh jejang pendidikan yang lebih tinggi. Kemampuan-kemampuan 
masyarakat tersebut akan dicerminkan dalam angka IPM. Jika penyerapan tenga kerja tinggi atau tingkat pengangguran menurun maka angka IPM akan tinggi.

Sehubungan dengan hal tersebut, kredit modal kerja lebih berpengaruh terhadap kesejateraan masyarakat dibandingkan dengan kredit investasi. Kredit modal kerja dalam kenyataannya adalah digunakan untuk pembelian persediaan barang dagangan atau persediaan bahwan baku dan bahan pembantu, termasuk kelangsungan upah tenaga kerja. Penggunaan modal usaha ini akan meningkatkan keuntungan perusahaan, atau perusahaan tetap bisa beroperasi di tengah-tengah persaingan usaha atau problem kenaikan upah minimum yang terjadi terus menerus tiap tahun. Jika keuntungan perusahaan bertambah atau perusahaan tetap survive di tengah persaingan, maka didistribusikan kepada tenaga kerja dan dikonversi oleh tenaga kerja dalam berbagai bentuk kesejahteraan hidup yang berupa daya beli, kemampuan memperoleh pendidikan dan kesehatan yang semakin meningkat.

\section{KESIMPULAN}

Pertumbuhan kredit investasi di kabupaten/kota di Jawa Timur selama periode studi sangat tinggi, tetapi tidak disertai dengan kemampuan untuk menyerap tenaga kerja, bahkan hubugannya adalah negatif, semakin tinggi kredit investasi, penyerapan tenaga kerjanya adalah semakin rendah. Penyebabnya semakin besar investasi, semakin bergeger ke padat modal daripada padat karya, yang membutuhkan tenaga kerja yang lebih sedikit. Ini membuktikan bahwa daya serap investasi tergadap tenaga kerja adalah semakin menurun. Akibat selanjutnya adalah hubungan negatif antara besarnya kredit investasi dengan kesejahteraan masyarakat.

Di sisi yang lain, kredit modal kerja meskipun relatif tidak menyebabkan penyerapan tenaga kerja, tetapi lebih mampu meningkatkan kesejahteraan masyarakat dalam jangka pendek karena membuat perusahaan tetap survive di tengah upah minimum yang terus meningkat dan persaingan usaha yang semakin ketat. Keberlangsungan usaha ini dikonversi oleh tenaga kerja dalam berbagai bentuk kesejahteraan misalnya daya beli yang semakin meningkat, pendidikan yang lebih baik dan tingkat kesehatan yang lebih baik. Maka kredit modal kerja lebih mampu mempengaruhi kesejahteraan masyarakat daripada kredit investasi, dalam jangka pendek.

Karena penyerapan tenaga kerja yang tinggi pada usaha mikro, kecil dan koperasi, lebih mampu meningkatkan kesejahteraan masyarakat daripada usaha menengah dan besar yang bersifat padat modal, disarankan perlunya penataan kembali dana investasi agar lebih mengarah pada investasi-investasi yang padat karya daripada padat modal. Caranya adalah peningkatan aksesebilitas usaha mikro, kecil dan koperasi terhadap kredit perbankan. Usaha-usaha tersebut antara lain penentuan tingkat bunga yang sangat rendah agar usaha-usaha tersebut bisa memanfaatkan dana investasi menjadi keuntungan atau dengan skema bagi hasil untuk membagi risiko antara pihak pengguna dana dengan penyedia dana.

\section{Daftar Rujukan}

Alatan, Tan Serlinda Deltania dan Basana Sautma Ronni, 2015. Pengaruh Pemberian Kredit Terhadap Ekonomi Regional Jawa Timur. Finesta Vol. 3, No. 1, (2015) 63-67. 
BPS, 2015a. Jumlah Perusahaan Industri Mikro dan Kecil Menurut Provinsi, 2013-2014. (online), Diakses dari http://bps.go.id/linkTabelStatis/view/ id/1789 tanggal 5 Mei 2015.

BPS, 2015b. Jumlah Perusahaan Industri Besar Sedang Menurut SubSektor, 2008-2013. (online), Diakses dari http://bps.go.id/linkTabelStatis/view/ id/1054tanggal 5 Mei 2015.

Dornbush, Rudiger, Stanley Fischer and Richard Starz, 2008. Makroekonomi. Edisi kesepuluh, Jakarta: PT Media Global Edukasi.

Fatihudin, Didin, 2011. Pengaruh Investasi Swasta dan Investasi Pemerintah terhadap Pertumbuhan Ekonomi, Penyerapan Tenaga Kerja dan Tingkat Kesejahteraan Masyarakat Kabupaten/Kota di Provinsi Jawa Timur. Disertasi, Pascasarjana Universitas Airlangga, Surabaya.

Gujarati, Damodar N. and Dawn C. Porter, 2013a. Dasar-Dasar Ekonometrika. Buku 2, Edisi 5, Jakarta: Salemba Empat.

Jhingan, M.L. 1983. The Economics of Development and Planning. New Delhi: Vicas Publishing House Ltd.

Kurniasari, Widita. 2010. Analisis Pengaruh Kredit Perbankan Dan Tenaga Kerja Terhadap Pertumbuhan Ekonomi Di Indonesia : Analisis Sektoral Tahun 2002 - 2008. Tesis. Fakultas Ekonomi Program Magister Perencanaan dan Kebijakan Publik Universitas Indonesia.

Qin, Duo, Marie Anne Caqs, Philipinas Quising and Xin-Hua He, 2006. How Much Does Investment Drives Economic Growth in China?. Elsevier Inc,. hlm. 751-774.

Samuelson, Paul A. and W. D. Nordhaus, 2004. Ilmu Makroekonomi. Edisi 17, Terjemahan Gretta dkk, Jakarta: PT Media Global Edukasi.

Sarwono, Jonathan. 2007. Anlisis Jalur untuk Riset Bisnis dengan SPSS, Yogyakarta: Andi.

Sen, Amartya , 1999. Development as Freedom. New York: Oxford University Press.

Todaro, M.P and Stephen C. Smith, 2006. Pembangunan Ekonomi. Edisi kesembilan. Terjemahan Munandar dan Puji, Jakarta: Penerbit Erlangga.

UNDP, 1994. Human Development Report. New York: Oxford University Press. 